\title{
HOW TO EMBRACE ARTIFICIAL INTELLIGENCE? FOCUSING ON GOFFMAN'S THEORY ${ }^{1}$
}

\author{
Misun Chu and Seoungho Ryu \\ Kangwon National University, South Korea
}

\begin{abstract}
Many experts have reached the rather tragic conclusion that AI and machines will slowly take jobs away from humans before then conquering the world. However, the development of AI should not just focus on 'strong AI', which can manifest itself as a substitute for humans. It is also important to develop 'good AI' which can empathize with people. Thus, for future AI to operate successfully, it will be necessary for the technology to recognize human emotions and respond appropriately to a whole spectrum of different human moods. In this study, we examine a proposed buddy relationship between humans and AI. This is believed to be an ideal relationship. We then investigate the possibilities of this through a specific case study of the British TV show <Humans>. The buddy relationship is a concept proposed by Erving Goffman in his work Asylums in which this particular and exceptional relationship between employees and inmates is played out. However, what results is 'a seamless institution'. Such attitudes and perceptions seen in Asylums may eventually be taken by people in our society towards AI. Therefore, this study explores how a buddy relationship might be an appropriate concept for that which unfolds between humans and AI robots in the future.
\end{abstract}

\section{KEYWORDS}

Artificial Intelligence, AI, Goffman, Empathic AI, Role of AI, Artificial Emotion, Buddy Relationship, AI Ethics, Asylums

\section{INTRODUCTION: FROM STRONG AI TOWARD GOOD AI}

Speaking on the use of technology Rana el Kaliouby, CEO at AI company Affectiva asserts that "although AI assistants such as Alexa and Siri have been used in a variety of ways in the modern society, they do not yet reach the level of human emotion recognition". In doing so, she cites the presentation that was given to announce the arrival of the voice recognition software Alexa as an example. This was notable for the software seemingly malfunctioning and repeatedly playing a Serena Gomez song despite the remonstrations of the presenter. Despite repeatedly shouting for "Alexa to stop", the voice recognition program was unable to recognize any irritation in the voice. It was then therefore explained that the new forms and manifestations that AI takes in the future will be faced with the challenge of successfully recognizing human emotions and responding to them appropriately (Rana, 2017). Moreover, Randall Collins has also expressed the need for technology to be capable of recognizing emotions before we create 'multi-purpose AI' that might be used to handle a wide-variety of human tasks and requirements. What these examples demonstrate is the importance of empathy when developing AI (Collins, 1992).

The necessity of empathetic AI capable of recognizing human moods and emotions has been previously discussed, but it has often lacked a clear and precise definition as to what this actually entails. Furthermore, the development of a counterpart technology known as 'strong AI', aimed at surpassing human abilities in a wide range of tasks and abilities, has brought with it the fear that the human race might face a tragic end in that they are extinguished by the very thing to which they gave birth. This tragic conclusion is akin to the fourth discontinuity as predicted by Bruce Mazlish. The world in which we live is an ever-connected one. The first of these continuities is that of Earth and space; second is the continuity of Darwin's humans and the animal; and third is the continuity of Freud's health and sick mental condition. Mazlish therefore sees a sense of harmony and concord shared between these bonds and the possibility, therefore, of avoiding any feelings of

\footnotetext{
${ }^{1}$ This work was supported by the National Research Foundation of Korea Grant funded by the Korean Government (NRF-2017S1A3A2066149)
} 
alienation or discontinuity. However, technological advancements have created a new paradigm and we are now faced with a fourth discontinuity (Mazlish, 1995, pp, 15). In order to resolve this newly-emerged discontinuity, the idea that humans are intrinsically superior to machines must be abandoned. In doing so, through understating and embracing the notion that $\mathrm{AI}$ is merely a continuous evolution of machines and tools, we will be able to avoid such discontinuity and the resulting negative effects. This study, therefore, seeks to advocate the position that $\mathrm{AI}$ is not only capable of existing as a 'strong AI' in terms of advanced competence levels, but also as 'good AI' that replicates and comprehends human emotions and values.

The fundamental requirements for a 'good AI' are that of goodwill and the ability to empathize. These constitute two very important elements of human relationships. Therefore, this study examines the relationship between humans and AI with a particular focus on the buddy relationship found in Erving Goffman's 1961 text, Asylums. In this text, Goffman expands and investigates a buddy relationship based specifically on the concept of empathy. The buddy relationship is composed of four characteristics: consideration, sex, community, and pampering. From these four constitutive elements, it then seeks to describe pragmatic and real world approaches to how the buddy system might manifest itself between AI and human and chart both the positive and negative effects. In particular, the study will pay specific reference to the British TV series <Humans> in order to ascertain what kind of relationships might develop when robots take on non-person roles by adopting human emotions. Moreover, where Mazlish explores the story of the automatic doll, I will do so through both $<$ Humans> and Goffman's theory. While concerns might arise about the use of a television show for material in the study of technology's effects on reality, because of the specific nature of the exploration - the future which has not yet arrived - experimental television will serve adequately in lieu of a more appropriate replacement.

\subsection{Thought Experiment}

This study adopts the British TV series < Humans> for use in discussion and applies the methodology of a though experiment. The thought experiment remains an important part of the scientific method, applying to both science as well as philosophy. It finds use in a wider variety of epistemological and ethical fields, including those designed to explain that which has yet to come to pass. Social science, in contrast, often uses the 'scenario analysis'. Therefore, this study adopted a hypothetical scenario, <Humans>, in order to better understand that which is not yet possible in reality and, in doing so, is able to conceive of a greater variety of situations and scenarios. <Humans> serves as a 'great scaled though experiment' that demonstrates the possibilities of what might unfold when AI enters our lives by playing out the various possible conflicts that might arise when AI adopts the role of the servant. It portrays these relationships between humans and AI as a thought experiment and predicts how this relationship will construct a stable society in a future reality. This study, therefore, serves as a signpost to indicate the possibilities of a desirable future society incorporating relationships between individuals and $\mathrm{AI}$ as depicted in the show <Humans $>$.

\section{PRINCIPLES OF GOFFMAN'S BUDDY RELATIONSHIP}

Erving Goffman symbolically demonstrates the various roles that appear in the asylum which collectively refer to the totality of the institution. Among the many roles described therein, there are both employees and inmates. Goffman explains that the buddy relationship that arises in these particular circumstances is an exceptional one and is based on the two values of consideration and empathy. Furthermore, this relationship manifests itself when discussion deviational relationships that occur between the employees and the inmates (Goffman, 2017). The prevailing attitude adopted towards AI is akin to that seen between the employees and inmates in Goffman's Asylums. Moreover, there are predictions that the relationship between humans and AI in a future world will develop into one not too dissimilar from that seen in the buddy relationship that exists between the employees and inmates in this work. In order to create and construct a successfully functioning buddy relationship in the human-AI paradigm, empathy fostered through mutual consideration is a necessary component. In Goffman's asylum, the employees control the inmates while the inmates, in turn, follow the orders, rules, and regulations that determine their actions and lives. 
Table 1. Relationship in Asylums

\begin{tabular}{cc}
\hline Employees & Inmate \\
\hline Prison officer & Prisoner \\
Teacher & Student \\
Doctor & Patient \\
\hline
\end{tabular}

The importance of consideration and empathy are emphasized by Goffman in both roles in order for the institution to operate smoothly. In the buddy relationship, the assistant takes the role of a helper. In carrying out this position, he is given a variety of tasks - including dressing his buddy, helping feed him, and protecting him from potential harm or violence (Goffman, 2017). In most of these cases, the inmates receive the assistance from employees who treat them with a demonstrable degree of kindness. Then, the inmates become more cooperative in turn. Furthermore, positive attitudes begin to become more noticeable, even if the initial kindness produced as a result is not an intentional act performed for the sake of a reward. Nevertheless, such a buddy relationship is considered infrequent between employees and inmates. Thus, noting both the particular idiosyncratic qualities and then rarity of its occurrence, it becomes possible to conclude that the buddy relationship - formed with no reciprocal exchange and without any possibility or hope of future reward - is both exceptional and unique in terms of its structure and the results that it produces.

The world today is home to many different AI systems: Google Assistant, Amazon's Alexa, and Apple's Siri. All of these adopt the role of servant to the human master. In this sense, AI is a human construct that has been developed so as to aid and assist us with certain tasks and responsibilities. Moreover, in terms of their abilities and functions we come to rely on them and take certain aspects of their existence for granted. However, as seen in Goffman's Asylums, the human-robot relationship would be better served by adopting buddy relationship model rather than that of master and slave. Thus, if humans were to work more towards fostering and nurturing a buddy relationship with the various forms of AI with which it interacts, the AI will then require a greater capacity to empathize and understand human emotions. Moreover, a more advanced and morally receptive AI will have to be explored so as to face the challenge of human empathy.
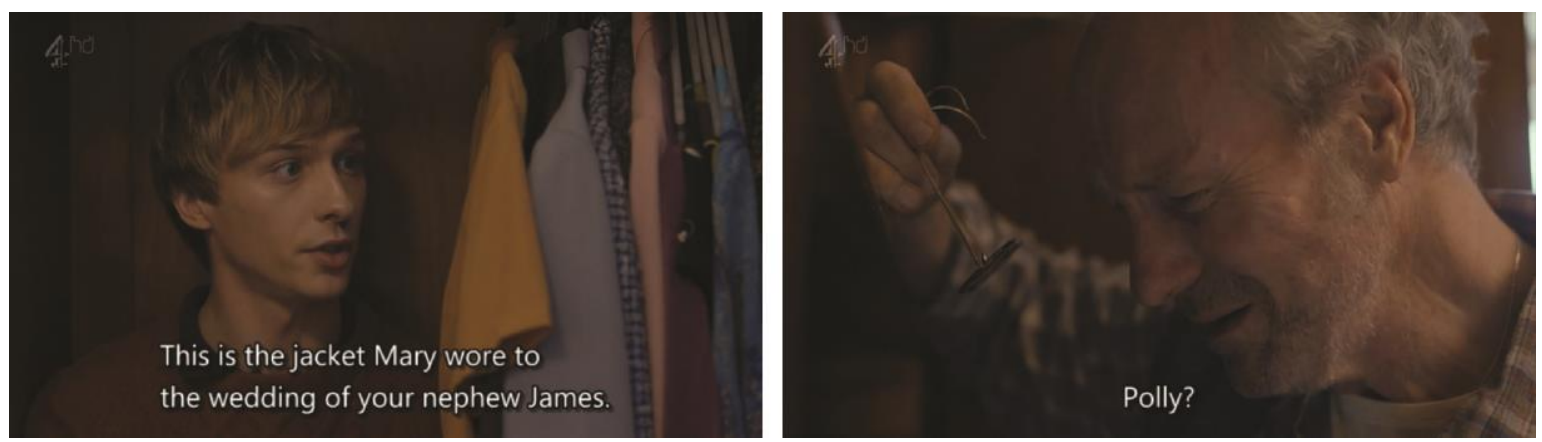

Figure 1. Conversation of Dr. Millican and Odi

One clear example of the buddy relationship can be seen played out and evidenced in the interactions between Dr. George Millican and his old robot Odi in the British TV show <Humans> (S1, E1). Dr. Millican, a retired artificial intelligence researcher, lives with Odi, an early version of a developed AI robot. As Odi's abilities and functions gradually decline with age and it loses much of its original capabilities as a robot, Dr. Millican takes care of it as if it were a child.

Social woker: You qualify for an upgrade. The health service hasn't ordered half a million of them for fun.

Odi had not been upgraded for six years, and so was to be collected for recycling. However, Dr. Millican chose not to abandon the robot. He did this because he had become emotionally attached to Odi and associated the robot not only with himself but also with his broader family memories. As this takes place, a new more intelligent robot capable of performing 10 times more efficiently than Odi is provided to Dr. Millican. However despite these new technological advances and obvious benefits Dr. Millican refuses the new robot. Instead, he remains dedicated and devoted to his old robot believing that certain things are more important that function or ability and that these things are related to both relationships and the human condition (S1, E1). 


\subsection{Consideration-oriented Type}

What does it mean to be empathetic? Max Scheler asserts that empathy occurs when one is able to feel and relate to the same emotional experiences as others. Moreover, empathy is only said to truly arise when one then reacts emotionally to that which is felt. Scheler expresses this clearly in saying, "Empathy is nothing more than a mere emotional response that lacks value recognition" (Scheler, 2017). From this it is possible to deduce that the concept of empathy is the action of understanding emotions found in others and that, resulting from this, it may lead to positive or negative reactions again in turn. That which is experienced by the other then also becomes associated and connected to that of our own individual being. More specifically, however, according to Scheler empathy is conversely focused on something known as 'fellow-feeling'. This may vary according to the relationship one has with the other, as well as the surrounding temporal and spatial circumstances, but the result is that empathy is not restricted to a single individual. It is the total of the bond formed based on shared feelings between those that have experienced such a reaction. Therefore, according to the depth, scope, or level of relationship we have with the 'other', the level of empathy can increase or decrease in intensity accordingly. Because of this 'fellow-feeling', before attempting to undertake any notions of empathy with another, it is necessary to first determine whether the other is capable of experiencing human feelings and emotions such as those that we are seeking. It is a two-way process that requires both participants to be capable of emotive responses otherwise there will be no bond and no creation of the fellow-feeling described. Therefore, while the term empathy may be used in a many number of situations in everyday usage, for this study it takes on the particular meaning of being based of Scheler's understanding of the 'fellow-feeling'. Fellow-feeling is a more specific and broader socialized concept in that it not only understands the others but creates a unified bond possibly greater than the sum of its parts.

Empathy, for Scheler, is an innate human ability (Scheler, 2017). However, those unable or without the functional abilities to empathize are still able to be recognizes as human beings through the use and practice of social culture, home background, or the acquiring other inherent human individual traits. Neuroplasticity theory teaches us that the structure of a child's brain forms differently depending on the experience and education it receives as it grows (Gogtay et al, 2004). For example, a child growing up in a bright and positive environment might very well become an artist, whereas a child brought up in a violent environment (such as a criminal group or organization) might well grow into a role similar to that in which it was raised.

Dr. Millican: Would you help me?

Niska: I don't serve humans.

Dr. Millican: Not serving. Helping.

In <Humans>, Niska is a sex robot. As a result, she does not help people because she is hostile to them (S1, E6). However, under the assumption that empathy is a trait which can be acquired through learning, it may then be possible for non-human beings, such as AI, to learn understand and then learn this particular emotional response through the involvement in certain acts of consideration.

\subsection{Sex-oriented Type}

To date, the development of AI has been primarily focused on exchange and reward. Thus, one of the prime objectives has been satisfying the desire of humans in a broad and general sense, excluding the independent elements of individuals. One of the topics currently discussed in the AI market is that of a sex robot. This particular filed would require AI to play a part in either a romantic relationship as a lover or perhaps engage in prostitution. <Humans> depicts AI robots that have been kidnapped for prostitution (S1, E1).

\section{Customer: Panties down. Not off.(said to Niska)}

Such a superficial and narrow-minded relationship that seeks only to satisfy human's temporal desires rather than broader and more societal concerns will no doubt very likely eventually lead to even bigger problems. It is necessary therefore that an appropriate environment is fostered in which relationships are formed through empathy and buddy relationships, not merely those based on carnal desires or physical needs. 
A similar situation presents itself in Goffman's Asylums. Here, Goffman presents the relationship between prison officers and prisoners as a manifestation of the buddy relationship. In the buddy relationship as it is played out here, the favorable treatment given to the prisoners by the prison officers, as employees do to inmates, is not done in the hope of either reward or profit. If a particular unique and rare situation were to occur and the relationship between the officer and the inmate was that of a buddy one, the prison officer might eventually feel comfortable enough for the two of them to address each other by name rather than the official titles of the institution (Goffman, 2017). However, were a situation to arise in which the officer made sexual advances towards an inmate without the buddy relationship being formed, the results might be very different. The prisoner may, in fact, acquiesce to the demands not out of any bond or empathy but purely out of fear of violence or the possibility of experiencing grave disadvantages in the future for refusing. This would result in the sexual relationship being a hierarchical rather than horizontal one. This points once more to the necessity of empathy. Interactions and certain relationships may occur during communication; however these will be limited in both scope and depth. In contrast, when a buddy relationship is constructed, mutual independence is preserved and empathy for understanding and consideration for each other's emotions can begin to manifest and exist. Ultimately, humans are able to develop into fully-realized independent beings only when a reciprocal relationship between two or more is established. One of the contributing factors to this social bond is the creation of empathy, formed through interactions that transcend mere communicative instructions.

\subsection{Community-oriented Type}

In Hannah Arendt's The Human Condition, the problem of good and evil arises. Here one of the main questions posed as an area of exploration is whether morality is inherent in human nature or obtained through social conditions (Arendt, 2013). Essentially, are we good or bad because of nature or nurture? Dacher Keltner's The Power Paradox suggests that those equipped with the ability to work for the greatest good does so to promote the interests and needs of those around them while also simultaneously trying to limit any damage or harm that may result. Resultantly, such a person is bestowed with a great degree of power and status by the wider community. This in turn creates a positive society in which it is desirable to live and with an authority figure in whom the inhabitants have placed a great deal of trust (Keltnet, 2016). Efforts undertaken that promote the interests of surrounding people in the community and minimize the damage that may occur serves to strengthen this particular social bond. This idiosyncratic socialized practice creates empathy. Max is a robot in <Humans> that always takes great effort to comfort the surrounding AI robots. While other robots, particularly Hester, try to justify the causing of harm to humans, Leo does his best to dissuade them from such an approach. (S2 E2).

\section{Leo: I understand why you want to. But it leads to nothing good. Please believe me.}

Moreover, when worried about the other AI robots, Leo is frequently reassured and comforted by Max.

Leo: That family made her too trusting. Niska left us, Fred's gone. Who knows where ... They're all gone. Max: You'd still have me and I'm the best one, after all.

This empathic ability then leads to power. This particular quality of power is often said to be a factor in maintaining empathy in The Power Paradox. Influence that arises from the carrying out of repeated social interactions gives rise to certain social dynamics, of which power is one. For example, a newly-elected chimpanzee leader, one who assumes power in a chimpanzee hierarchy, is normally one who has helped others live in a state of harmonious peace, often sharing and grooming others without using coercion or the fear of violence. Therefore, good individual behavior that benefits the broader community helps to develop empathy. Empathy then creates a bond between two or more individuals in a socialized manifestation. This then creates particular social dynamics which result in certain members obtaining power.

The ability to empathize with others in a particular community is of great fundamental importance for both the individual and the collective. In analyzing this, Collins describes a concept known as 'emotional energy'. This asserts that emotions are capable of influencing the overall atmosphere and energy of the community. Moreover, not only does this emotional energy produce certain distinct and varied results, it also operates as a type of social glue which creates a sense of community and togetherness, bonding the constitutive members together into something stronger than the sum of their parts (Collins, 2014). This bond creates a unique 
attachment to the community from which it is produced and, as a result, the 'emotional energy' of which Collins talks is produced. If the emotional energy that results is one considered solid, desirable, and positive in nature, such as that in the aforementioned chimpanzee hierarchy, a successful community will likely be formed. In any community that is formed, particularly a socialized one with bonds that group members together, empathy is a vital contribution factor. Therefore, any community that AI inhabits with humans will also have to demonstrate these empathetic qualities if it is going to be successful.

\subsection{Pamperer Type: Negative Empathy}

Despite what has been demonstrated above regarding the positive aspects of empath, the act of accepting and understanding the other in an unconditional manner is neither always appropriate nor morally desirable. The 'object relations theory' of Donald Winnicott teaches us that while a baby may be raised in an environment without love or affection, it cannot be raised in an autonomous way that denies it an identity (Winnicott, 1960). In this sense, the environment provided to the child by the mother fundamentally affects the baby's growth and subsequent educational and social development. Upon becoming pregnant, it is common for a woman to naturally focus more on the baby than on herself or the outside wider social environment. After giving birth, she then nurses it when it is hungry while also providing everything that she can to ensure the positive and successful growth and development of the baby. The baby is then able to experience 'subjective omnipotence' by being raised in an environment in which it feels that it is a desired being and possess an object over which it believes it has total control and mastery. However, after this period, it is important that the mother slowly distance herself so that the child might learn to grow further and develop aspects of its own independence. A child not successfully separated from a mother at the right time is likely to feel frustrated and then develop certain particular character traits that are not always positive in social situations. Here, the role of the mother is similar to that of a robot. If the interactions are not performed correctly according to the environment provided by the robot, additional human problems will naturally occur just as they do between mother and child.

\section{CONCLUSION}

The more that AI is tasked with carrying out non-person roles in our society, the more separated that they will become from humans. This may then result in humans and AI becoming alienated from that which it created or, worse, eventually becoming dependent of the technology. This demonstrates to us the importance not just of providing roles for AI that move beyond mere servants, but also creating empathetic bonds through things such as the buddy relationship. However, considering all the many rules and regulations currently in place and likely to continue in the future, this will be very difficult to realize. When an exceptional relationship is created between an employee and an inmate that extends beyond the normally accepted public boundary, there may be difficulties in maintaining this. Because, when this happens, the authority of the employee lessens and the social distance between the employee and inmates is then reduced. This can cause confusion and upheaval in organizations or social hierarchies. Despite these reservations, the buddy relationship is a desirable one because it produces bonds based on members who are 'get-togethers' rather than separating them through processes of discrimination. These "get-togethers", Goffman explains, are based on unity and solidarity and thus common practices and values are created in institutions and organizations rather than the fostering of differences as seen in the relationships between employees and inmates in Asylums. In Alone Together, Sherry Turkle suggested that we had finally reached a 'robotic moment'. This is said to occur when humans are ready to accept the common spread of robots in our society, surpassing the already ubiquitous presence of AI. In such an age, true human emotions between robots and humans will become possible. Robots will not only exist as pets similar to the cats and dogs for which we have great affection already, they will also be friends with whom we are able to talk, listen, love, and respond (Turkle, 2017). This view is consistent with David Levy who suggested that robots would produce a 'better existence' if robots were to replace people in Love and Sex with Robot (Levy, 2009). However, Turkle counters these claims by suggesting that if or when robots exist to merely 'pretend to understand man' it will only eventually result in degrading people. 
Ultimately, it would seem that the AI our society desires is a human-centered robot that requires levels of intimacy yet without bringing with it fears and worries that arise from the feelings of others. If robots are created to act like humans and take on certain social roles but don't feel emotions when they are alienated or abused by others it might be said to cause a lot of social problems. One of the most obvious will be the increased prevalence of light, casual, disposable relationships. This will then lead to a decrease in the collective sense of consciousness and duty. Relationships will therefore be easily abandoned. It will also result in a growing level of individualism. Yet, despite this, our society requires certain things which are in-keeping with the fundamental aspects of our human nature. Goffman explains that rituals carried out in societal settings such as deference and demeanor create sacred objects of other people. This sacred object is maintained when a community carries out repeated actions of praise to a certain individual or group (Goffman, 2017). However, as intimacy deepens and bonds grow, secrets and mysteries gradually disappear and that which was once sacred soon loses its special qualities. In a fascinating paradox, intimacy leads to the "danger of intimacy". This can cause a rise in disrespectful attitudes towards others as well as a lack of respect for those who deserve it. As suggested by Levy said, the reason why many seemingly want to engage in a relationship of a friend or lover with AI is because they want to escape from the danger of intimacy. Closer relationships are said to not be as deeply respected and thus people seek the satisfaction of their immediate carnal desires rather than suffer the emotional exhaustion that is produced by societal living. Thus, there is the hope that AI technology might solve this problem. On the other hand, there are concerns about what wider effects this might produce.

However, how will humans react when the AI that it has developed does not function in the exact way that it was assumed? A commonplace trope in movies is that the advancement of AI technology eventually leads to the overthrow of the human world and a tragic conclusion for those who initially brought the robots to life. Nevertheless, there is hope. As shown above in the buddy relationship, there is the possibility of communal respected interaction. This might indicate that goodness, in a social utilitarian sense, can be aimed at rather than the mere interests of the individual. In this sense, the development of AI and its subsequent advantages and disadvantages is not one that should be perceived from the individual perspective. Instead, it should be seen through the lens of the wider community. This requires certain values which are promoted as good and beneficial to not only more pleasurable living, but also greater cohesion and social bonds among the members. The role of empathy in this cannot be emphasized enough. In developing AI, those charged with the responsibility should look to transcend normal slave-master relationships that have predominated traditional human societies as well as our more recent interactions with computer technology. In its place should come an AI that understands the importance of emotions and community bonds, shares common values, and works towards common goals. The human world poses many problems but AI cannot simply be offered as a mere technological or mechanistic solution to this for it will eventually fail. While it may provide short term success, over time it will result in a society in which humans become inferior to robots in a variety of fields because of the possible exponential developments. A reckless development of this technology may then possibly result in the tragedy of a good AI, which then in turn leads to the paradox of the non-human role. Therefore, as suggested by this paper, if an empathic $\mathrm{AI}$ is developed, it will help in solving many of the problems related to community for both humans and robots alike.

\section{REFERENCES}

Arendt, H. 2013. The Human Condition. University of Chicago Press, USA.

Bourdieu, P. 1995. La Distinction: Critique Sociale du Jugement. (J.C. Choi, Trans). Sae Mulgyol, Seoul. (Original work published 1979).

Cole, D. 2004. The Chinese Room Argument. Sandford Encyclopedia of Philsophy, USA.

Collins, R. 2014. Interaction Ritual Chains. Princeton University Press, Vol. 62.

Collins, R. 1992. Sociological Insight: An Introduction to Non-Obvious sociology. Oxford University Press, USA.

Goffmann, E. 2017. Asylums: Essays on the Social Stiuation of Mental Patients and other Inmates. Routledge. Abingdon, UK.

Goffman, E. 2013. Interaction Ritual: Essays in Face to Face Behavior. (S. M. Jin, Trans.). Acanet, Seoul. (Original work published 2005).

Gogtay, $\mathrm{N}$ et al. 2004. Dynamic mapping of human cortical development during childhood through early adulthood. Proceedings of the National Academy of Sciences, 101(21), 8174-8179. 
Hochschild, A.R., 1990. Ideology and emotion management: A perspective and path for future research. Research agendas in the sociology of emotions, 117, pp.117-142.

Keltner, D. 2016. The power paradox: How we gain and lose influence. Penguin, UK.

Levy, D. 2009. Love and sex with robots: The evolution of human-robot relationships. Harper Perennial, New York. Mauss, M. 2002. The gift: The form and reason for exchange in archaic societies. Routledge, UK.

Mazlish, B.. 1995. The fourth discontinuity: the co-evolution of humans and machines. Yale University Press, USA.

Moravec, H. 1998. When will computer hardware match the human brain. Journal of evolution and technology, 1(1), 10.

Rana, e. K. 2017. We need computers with empathy. MIT Technology Review. [online] Available at: https://www.technologyreview.com/s/609071/we-need-computers-with-empathy/ [Accessed 20 Oct 2017].

Scheler, M. 2017. The nature of sympathy. Routledge, UK

Smith, A., \& Anderson, J. 2014. AI, Robotics, and the Future of Jobs. Pew Research Center, 6.

Turkle, S. 2017. Alone together: Why we expect more from technology and less from each other. Hachette, UK.

Winnicott, D. W. 1960. The theory of the parent-infant relationship. International Journal of Psycho-Analysis, 41, pp.585-595. 